\title{
Gender differences in the management and outcome of patients with acute coronary artery disease
}

\author{
R A Raine, N A Black,T J Bowker, D A Wood
}

J Epidemiol Community Health 2002;56:791-797

\begin{abstract}
Study objectives: To compare the clinical management and health outcomes of men and women after admission with acute coronary syndromes, after adjusting for disease severity, sociodemographic, and cardiac risk factors.

Design: Prospective national survey of acute cardiac admissions followed up by mailed patient questionnaire two to three years after initial admission.

Setting: Random sample of 94 district general hospitals in the UK.

Patients: 1064 patients under 70 years old recruited between April 1995 and November 1996.

Main results: Of the 1064 patients recruited, $126(11.8 \%)$ died before follow up. Of the 938 survivors, $719(76.7 \%)$ completed a follow up questionnaire. There were no gender differences in the use of cardiac investigations during the index admission or follow up period. However, male patients with hypertension were more likely to undergo rehabilitation compared with female hypertensive patients (OR 2.01, $95 \% \mathrm{Cl} 0.85$ to 4.72 ). Men were also more likely to undergo coronary artery bypass grafting ( $C A B G)$ than women (OR 1.90,95\% 1.21 to 3.00), but there was no gender difference in the use of revascularisation overall $(p=0.14)$. An indirect indication that the gender differences in $C A B G$ were not attributable to bias was provided by the lack of gender differences in health outcomes, which implies that patients received the care they needed.

Conclusions: Despite the extensive international literature referring to a gender bias in favour of men with coronary heart disease, this national survey found no gender differences in the use of investigations or in revascularisation overall. However, the criteria used for selecting percutaneous transluminal coronary angioplasty compared with CABG requires further investigation as does the use of rehabilitation. It is unclear whether the clinical decisions to provide these procedures are made solely on the basis of clinical need.
\end{abstract}

See end of article for authors' affiliations

Correspondence to: Professor R A Raine, Department of Public Health and Policy, London School of Hygiene and Tropical Medicine, Keppel Street, London WCIE 7HT, UK;

rosalind.raine@lshtm.ac.uk

Accepted for publication 5 March 2002
A fundamental tenet of the British NHS is that health care should be provided equitably, that is, solely according to clinical need. Yet there is evidence that gender bias exists in the use of cardiac services. ${ }^{1}$ In practical terms, gender bias can result in either over-treatment in the favoured group (in this case, men) or under-treatment in the neglected group. Given the importance of coronary artery disease as a cause of morbidity and mortality in both men and women in the United Kingdom, the existence of gender bias would be of considerable social and clinical importance. ${ }^{23}$

Studies conducted in the NHS have serious limitations as they have relied on inadequate, routinely collected data, on retrospective data collection, or have not examined the entire management pathway from admission with acute ischaemia to revascularisation. ${ }^{4-15}$ Failure to study the entire management pathway is important because studies from other countries suggest that gender differences occur early on in the clinical management of patients-in the investigation of coronary artery disease rather than in the subsequent use of revascularisation. ${ }^{1}$

To overcome the limitations of previous studies, we investigated the complete management pathway of patients, admitted to a random sample of district general hospitals, with a diagnosis of acute myocardial infarction or myocardial ischaemia to see if there was evidence of inequity between men and women in the way they were managed.

\section{METHODS}

This was a follow up of patients recruited for the Survey of Acute Myocardial Infarction and Ischaemia (SAMII). Details of that study have been reported elsewhere. ${ }^{16}$ Briefly, a sample of 94 district general hospitals in the UK were randomly selected. Each hospital was asked to recruit 12 consecutive patients (six female and six male) less than 70 years old who, in the opinion of the admitting medical team, presented with the symptoms and signs of acute myocardial infarction or acute myocardial ischaemia. A total of 1064 patients, 503 women and 561 men were recruited between April 1995 and November 1996. This sample size was calculated to provide a $90 \%$ probability of detecting a significant difference in the use of revascularisation (where one really existed) with precision of $95 \%$. The power calculation was based on gender differences in revascularisation found in an English retrospective study of the management of a cohort admitted with acute coronary heart disease." For each patient, information was collected prospectively on standardised forms. Data on demographic characteristics and health status on admission, management, and hospital outcome were collected by consultant cardiologists or their research nurses (both of whom had attended a training session). Risk factor and family history data were provided directly by the patients themselves (table 1). Data supplied by clinicians was checked for completeness and for outlying values by the research team, and referred back for completion or correction.

The indicators of disease severity, and therefore, of the need for health care, that were collected were the presence of a Q wave infarct, clinical, or radiological evidence of heart failure, an abnormal rise in creatine kinase levels, recurrent signs or

Abbreviations: CABG; coronary artery bypass grafting; PCTA, percutaneous transluminal coronary angioplasty 
Table 1 Information collected about patients' index admission and at follow up

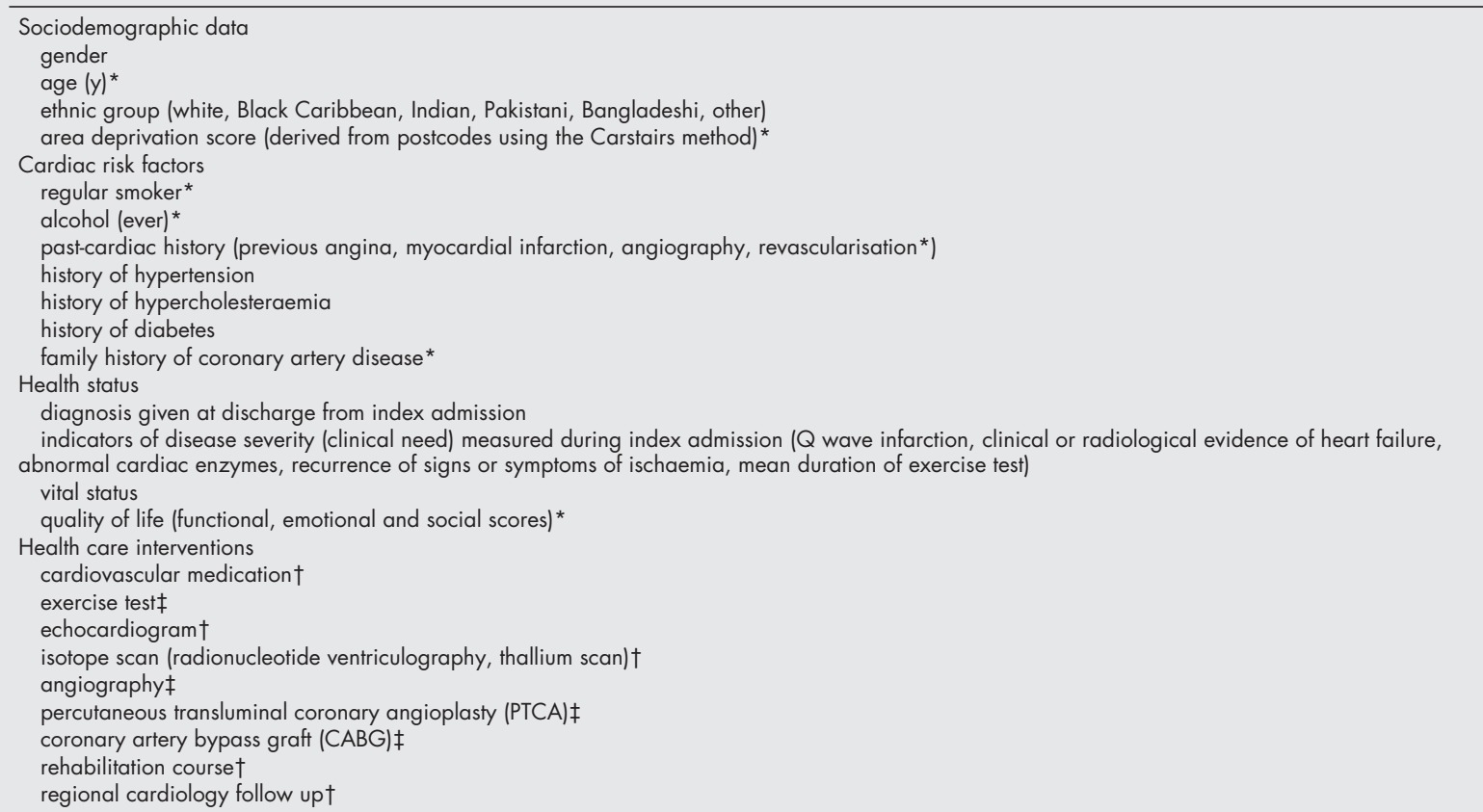

*Data provided by patient. †Health care intervention reported by clinician on admission only. łHealth care intervention reported at admission by clinician, and at follow up by patient.

symptoms of ischaemia and the mean duration of the exercise test performed just before discharge. These variables are recommended by the American College of Cardiology/ American Heart Association as determinants of the appropriateness of indication for angiography. ${ }^{17}$

Surviving patients were followed up in 1998-that is, between two and three years after their initial admission, by means of a mailed questionnaire. Non-responders were sent two reminders. Information was sought on investigations and revascularisation procedures performed during the intervening period, and on the respondents' current state using the Quality of Life after Myocardial Infarction Questionnaire II. ${ }^{18}$ In all the analyses, where possible data on the initial admission that had been provided by patients (rather than clinicians) were used as all follow up data were from patients. Thus, when the same question was asked of patients and clinicians, patients' responses were used for consistency.

Male patients were compared with female patients with respect to their sociodemographic, cardiac risk factor, and health status characteristics and their use of health care interventions. The $\chi^{2}$ test was used to compare categorical variables and the $t$ test for independent samples was used to compare the distribution of continuous variables.

Gender differences in the use of health care interventions were further analysed by examining the effect of gender after adjusting for indicators of disease severity and for potential confounders (discharge diagnosis, sociodemographic, and cardiac risk factors) using multiple variable logistic regression. ${ }^{20}$ Models including interactions between variables were then compared with models without the interaction term. The variables chosen were those where, if gender was significantly associated with the use of interventions, it was intuitively plausible that the association may differ depending on whether the discharge diagnosis was angina (more common in women) or myocardial infarction (more common in men) and according to the presence or absence of indicators of clinical need (heart failure and recurring signs and symptoms) and other potential confounders. The final model was assessed using the likelihood ratio test to check whether adding any variables led to a significant improvement in model fit. To undertake analysis of inter- actions, continuous and categorical variables were recoded as dichotomous: age was recoded as under 50 years or 50 years and over; ethnic group as white or non-white; Carstairs' scores of social deprivation as less than zero (affluent) and more than zero (deprived).${ }^{19}$ The statistical software package, SPSS version 8.0 was used. ${ }^{21}$

\section{RESULTS}

\section{Reliability of the follow up questionnaire}

Intra-rater reliability was determined by sending a repeat questionnaire 12 weeks after the first one to a random sample of 80 patients, 59 of whom responded. Cohen's $\kappa$ was calculated for each item coded as a categorical variable. The level of agreement for every item was good to excellent $(\kappa$ scores ranged from 0.62 , $\mathrm{p}$ value $<0.0001$, to complete agreement), with the exception of waiting for exercise tests $(\kappa=0.26, \mathrm{p}$ value $=0.0005)$ and angiography $(\kappa=0.30, \mathrm{p}$ value $=0.0003)$. The Pearson product moment correlation coefficient was used to measure the degree of association for each of the quality of life domains separately and for the global domain. The correlation coefficients were above 0.90 for all domains.

\section{Response to follow up questionnaire}

Of the 1064 patients recruited to the study, 126 (11.8\%) died within the follow up period. Of the 938 surviving patients, 719 $(76.7 \%)$ returned the follow up questionnaire. A comparison showed that there were no significant gender differences between responders (53.1\% male) and non-responders $(51.9 \%$ male, $\mathrm{p}=0.70$ ) or between responders and non-responders who had died $(53.1 \%$ male versus $58.2 \%$ male, $p=0.30)$. A comparison between responders and non-responders (table 2) also showed that there were no statistically significant differences by age, most cardiac risk factors, experience of exercise testing or isotope scanning, having a follow up plan for angiography or regional centre referral. However, responders were more likely to be white, to live in an affluent area, be a non-smoker, have no history of coronary disease, have less severe disease (as indicated by the presence of Q waves and 
Table 2 Characteristics of responders compared with non-responders

\begin{tabular}{|c|c|c|c|c|c|c|c|}
\hline & \multicolumn{2}{|c|}{ Responders $(n=719)$} & \multicolumn{4}{|c|}{ Non-responders $(n=345)$} & \multirow{2}{*}{$\mathrm{p}$ Value } \\
\hline \multicolumn{7}{|l|}{ Sociodemographic characteristics } & \\
\hline Male & 382 & $(53.1)$ & & 179 & (51.9) & & 0.70 \\
\hline Mean age (y) & 62.2 & & & $61 . \varepsilon$ & & & 0.44 \\
\hline White & 686 & (95.4) & & 316 & (91.6) & & 0.015 \\
\hline Carstairs mean deprivation score & $-0.1 \xi$ & & $n=652$ & 0.3 & & $n=318$ & 0.003 \\
\hline Regular smoker & 227 & $(43.5)$ & $n=522$ & 124 & (51.2) & $n=242$ & 0.05 \\
\hline Alcohol (ever) & 612 & $(89.1)$ & $n=686$ & 265 & (87.2) & $n=304$ & 0.35 \\
\hline \multicolumn{8}{|l|}{ Family history* } \\
\hline Hypertension & 221 & (32.7) & $n=675$ & 107 & $(36.0)$ & $n=297$ & 0.45 \\
\hline Coronary artery disease & 437 & (64.5) & $n=677$ & 184 & $(60.5)$ & $n=304$ & 0.16 \\
\hline Hypercholesterolaemia & 81 & $(12.1)$ & $n=670$ & 32 & $(10.8)$ & $n=297$ & 0.59 \\
\hline \multicolumn{8}{|l|}{ Past medical history } \\
\hline Diabetes & 70 & (10.2) & $n=684$ & 43 & (13.9) & $n=309$ & 0.09 \\
\hline Hypertension & 247 & $(36.6)$ & $n=674$ & 123 & (40.9) & $n=301$ & 0.21 \\
\hline Angina & 296 & (43.9) & $n=674$ & 155 & (51.0) & $n=304$ & 0.04 \\
\hline Acute myocardial infarction & 232 & $(34.6)$ & $n=670$ & 126 & $(41.7)$ & $n=302$ & 0.03 \\
\hline Hypercholesterolaemia & 187 & $(28.6)$ & $n=654$ & 82 & (28.3) & $n=290$ & 0.92 \\
\hline Previous CABG & 46 & (6.7) & $n=683$ & 28 & (9.1) & $\mathrm{n}=307$ & 0.19 \\
\hline Previous PTCA & 40 & (5.8) & $n=684$ & 22 & (7.1) & $n=308$ & 0.44 \\
\hline Previous angiogram & 78 & (72.2) & $n=108$ & 38 & (66.7) & $n=57$ & 0.46 \\
\hline \multicolumn{8}{|l|}{ Indicators of disease severity } \\
\hline$Q$ wave infarction & 251 & (65.5) & $n=383$ & 115 & (74.2) & $\mathrm{n}=155$ & 0.05 \\
\hline Clinical / radiological evidence of heart failure during admission & 141 & $(19.9)$ & $n=708$ & 88 & (26.4) & $n=333$ & 0.03 \\
\hline Abnormal CK $\dagger$ & 326 & (55.0) & $n=593$ & 132 & (48.9) & $n=270$ & 0.10 \\
\hline Recurrence of signs / symptoms of ischaemia & 277 & $(39.2)$ & $n=706$ & 120 & (35.7) & $n=336$ & 0.27 \\
\hline $\begin{array}{l}\text { If recurrent ischaemia, mean number of times (median, } \\
\text { interquartile range) }\end{array}$ & \multicolumn{2}{|c|}{$6.40(2.0,1.0-4.0)$} & $\mathrm{n}=272$ & \multicolumn{2}{|c|}{$3.62(2.0,1.0-4.3)$} & $\mathrm{n}=114$ & 0.61 \\
\hline $\begin{array}{l}\text { Mean duration of pre-discharge exercise test [mins] (median, } \\
\text { interquartile range) }\end{array}$ & \multirow{2}{*}{\multicolumn{2}{|c|}{$7.41(7.1,4.5-9.5)$}} & $n=80$ & \multicolumn{2}{|c|}{$6.48(6.4,4.0-9.0)$} & $n=31$ & 0.28 \\
\hline \multicolumn{7}{|l|}{ Discharge diagnosis } & \\
\hline Acute myocardial infarction & 383 & (54.3) & $n=705$ & 155 & (46.7) & $n=330$ & 0.03 \\
\hline Angina & 271 & (38.4) & $n=705$ & 133 & $(40.8)$ & $n=326$ & 0.47 \\
\hline Non-cardiac cause & 20 & $(2.8)$ & $n=705$ & 15 & (4.5) & $n=331$ & 0.16 \\
\hline Further investigation required & 28 & $(4.0)$ & $n=704$ & 22 & (6.7) & $n=326$ & 0.05 \\
\hline \multicolumn{8}{|l|}{ Diagnostic procedures and follow up plans } \\
\hline Echocardiogram & 103 & (14.3) & & 34 & (9.9) & & 0.04 \\
\hline Radionucleotide ventriculography & 6 & (0.8) & & 2 & $(0.6)$ & & 0.65 \\
\hline Thallium scan & 1 & (0.1) & & 1 & $(0.3)$ & & 0.60 \\
\hline On site angiogram & 18 & $(2.7)$ & $n=677$ & 16 & (4.9) & $n=326$ & 0.07 \\
\hline Pre-discharge exercise test & 83 & $(11.7)$ & $n=710$ & 31 & (9.3) & $n=335$ & 0.24 \\
\hline Local outpatient appointment & 614 & (88.3) & $n=695$ & 260 & (84.1) & $n=309$ & 0.07 \\
\hline Cardiac rehab. course & 274 & (41.9) & $n=654$ & 84 & (29.5) & $\mathrm{n}=285$ & 0.0001 \\
\hline Follow up plan for on site angiogram & 26 & $(4.1)$ & $n=632$ & 16 & (5.6) & $\mathrm{n}=285$ & 0.32 \\
\hline Referral to regional centre & 119 & (18.3) & $n=650$ & 47 & $(16.5)$ & $n=284$ & 0.52 \\
\hline
\end{tabular}

heart failure) and yet have a discharge diagnosis of myocardial infarction, and be referred for cardiac rehabilitation.

\section{Characteristics of male and female responders}

Women responders were significantly older and more likely to abstain from alcohol than men (table 3). While women were more likely to have certain cardiac risk factors (personal history of hypertension and diabetes, family history of hypertension and coronary artery disease), they were less likely to have a history of myocardial infarction or of previous percutaneous transluminal coronary angioplasty (PTCA) (table 3). Women were less likely to have a discharge diagnosis of myocardial infarction (which was significantly less likely to be a Q wave infarct). Despite these differences, there were no significant gender differences in survival or in the quality of life of survivors-overall quality of life (mean scores: men 4.83 compared with 4.91 in women), emotional domain (4.82 versus 4.86 ), physical domain (4.72 versus 4.83 ), and social domain (4.94 versus 5.08). (The maximum possible quality of life score in each of the three domains was seven).

\section{Effect of gender on the likelihood of a healthcare intervention}

During their index admission, gender differences were observed among the 719 responders to the follow up questionnaire (table 4). Men were more likely than women to undergo echocardiography, to receive a local outpatient follow up appointment, and to be referred for a course in cardiac rehabilitation. However, when all the original 1064 patients were considered, the only gender difference observed was referral for rehabilitation.

During the follow up period men were more likely to undergo coronary artery bypass grafting (CABG) than women (table 5). There were no other significant gender difference in investigations or cardiac procedures undergone or awaited. Although women were more likely to undergo PTCA, this was not statistically significant.

Effect of potential confounders on the relation between gender and rehabilitation

To examine further the association between gender and the use of rehabilitation among responders $(n=719)$, the odds ratio for the entire baseline sample $(\mathrm{n}=1064)$ was calculated (OR 1.39, 95\% CI 1.07 to 1.81 ). It remained significant after adjusting for each potential confounder, including disease severity, in turn and cumulatively. However, the odds ratio was no longer statistically significant when either the patient's discharge diagnosis $(1.28,95 \%$ CI 0.94 to 1.73$)$ or the use of revascularisation was taken into account $(1.22,95 \%$ CI 0.80 to 1.89$)$.

Interactions between other potential confounders and gender were assessed. Hypertension significantly improved the fit 
Table 3 Sociodemographic characteristics, cardiac risk factors, and indicators of initial disease severity in male and female responders

\begin{tabular}{|c|c|c|c|c|c|c|c|}
\hline & \multicolumn{2}{|c|}{ Men $(n=382)$} & \multicolumn{4}{|c|}{ Women $(n=337)$} & $\mathrm{p}$ Value \\
\hline \multicolumn{8}{|l|}{ Sociodemographic characteristics } \\
\hline Mean age (ys) & \multicolumn{2}{|c|}{60.7} & \multicolumn{3}{|c|}{64.0} & \multicolumn{2}{|r|}{$<0.001$} \\
\hline White & 362 & (94.8) & & 324 & $(96.1)$ & & 0.38 \\
\hline Carstairs mean deprivation score & \multicolumn{2}{|c|}{-0.13} & $n=352$ & \multicolumn{2}{|c|}{-0.24} & $n=300$ & 0.59 \\
\hline Regular smoker & 136 & (43.9) & & 91 & $(42.9)$ & & 0.83 \\
\hline Alcohol (ever) & 353 & (96.2) & & 259 & (81.2) & & $<0.001$ \\
\hline \multicolumn{8}{|l|}{ Family history* } \\
\hline Hypertension & 98 & $(26.9)$ & $n=364$ & 120 & $(39.5)$ & $n=306$ & 0.003 \\
\hline Coronary artery disease & 221 & $(60.2)$ & $n=382$ & 216 & (69.7) & $\mathrm{n}=337$ & 0.01 \\
\hline Hypercholesterolaemia & 39 & $(10.7)$ & $n=365$ & 42 & (13.8) & $n=305$ & 0.33 \\
\hline \multicolumn{8}{|l|}{ Past medical history } \\
\hline Diabetes & 30 & $(8.2)$ & $n=382$ & 40 & (12.7) & $n=337$ & 0.05 \\
\hline Hypertension & 104 & $(28.6)$ & $n=382$ & 143 & (46.1) & $n=337$ & $<0.001$ \\
\hline Angina & 154 & $(42.7)$ & $n=382$ & 142 & $(45.4)$ & $n=337$ & 0.48 \\
\hline Acute myocardial infarction & 141 & $(39.4)$ & $n=382$ & 91 & $(29.2)$ & $n=337$ & 0.006 \\
\hline Hypercholesterolaemia & 102 & $(28.6)$ & $n=382$ & 85 & $(28.6)$ & $n=337$ & 0.99 \\
\hline Previous CABG & 30 & $(8.2)$ & $n=366$ & 16 & $(5.0)$ & $n=317$ & 0.10 \\
\hline Previous PTCA & 29 & (7.9) & $n=365$ & 11 & (3.4) & $n=319$ & 0.01 \\
\hline \multicolumn{8}{|l|}{ Indicators of disease severity } \\
\hline$Q$ wave infarction & 157 & (70.4) & $n=223$ & 94 & $(58.8)$ & $n=160$ & 0.02 \\
\hline $\begin{array}{l}\text { Clinical / radiological evidence of heart failure during } \\
\text { admission }\end{array}$ & 81 & (21.4) & $n=379$ & 60 & $(18.2)$ & $n=329$ & 0.30 \\
\hline Abnormal CK† & 195 & $(60.6)$ & $n=322$ & 131 & $(48.3)$ & $\mathrm{n}=271$ & 0.003 \\
\hline Recurrence of signs / symptoms of ischaemia & 142 & $(37.4)$ & $n=380$ & 135 & $(41.4)$ & $n=326$ & 0.27 \\
\hline $\begin{array}{l}\text { If recurrent ischaemia, mean number of times (median, } \\
\text { interquartile range) }\end{array}$ & \multicolumn{2}{|c|}{$3.22(2.0,1.0-3.0)$} & & \multicolumn{2}{|c|}{$3.60(2.0,1.0-4.0)$} & & 0.42 \\
\hline $\begin{array}{l}\text { Mean duration of pre-discharge exercise test ( } \mathrm{min} \text { ) } \\
\text { (median, interquartile range) }\end{array}$ & \multirow{2}{*}{\multicolumn{2}{|c|}{$7.34(8.0,5.0-9.2)$}} & $(n=41)$ & \multicolumn{2}{|c|}{$7.47(6.6,4.4-10.2)$} & $(n=39)$ & 0.81 \\
\hline \multicolumn{6}{|l|}{ Discharge diagnosis } & & \\
\hline Acute myocardial infarction & 223 & $(59.2)$ & $n=377$ & 160 & $(48.8)$ & $n=328$ & 0.01 \\
\hline Angina & 128 & (34.1) & $\mathrm{n}=375$ & 143 & $(43.3)$ & $n=330$ & 0.01 \\
\hline Non-cardiac cause & 10 & $(2.6)^{\prime}$ & $n=378$ & 10 & $(3.1)$ & $n=327$ & 0.74 \\
\hline Further investigation required & 14 & (3.7) & $n=376$ & 14 & $(4.3)$ & $\mathrm{n}=328$ & 0.71 \\
\hline
\end{tabular}

Table 4 Diagnostic procedures and follow up plans during index admission in male and female responders

\begin{tabular}{|c|c|c|c|c|c|}
\hline & Men $(n=38$ & & Women $(n=$ & 337) & $\mathrm{p}$ Value \\
\hline Echocardiogram & $64(16.8)$ & & $39(11.6)$ & & 0.05 \\
\hline Radionucleotide ventriculography & $3(0.8)$ & & $3(0.9)$ & & 0.88 \\
\hline Thallium scan & $1(0.3)$ & & 0 & & 0.35 \\
\hline On site angiogram & $8(2.2)$ & $n=364$ & $10(3.2)$ & $n=313$ & 0.42 \\
\hline Pre-discharge exercise test & $42(11.0)$ & $\mathrm{n}=381$ & $41(12.5)$ & $n=329$ & 0.55 \\
\hline Local outpatient appointment & $342(91.9)$ & $n=372$ & $272(84.2)$ & $n=323$ & 0.002 \\
\hline Cardiac rehab. course & $167(47.6)$ & $n=351$ & $107(35.3)$ & $\mathrm{n}=303$ & 0.002 \\
\hline Follow up plan for on site angiogram & $14(4.1)$ & $n=339$ & $12(4.1)$ & $\mathrm{n}=293$ & 0.93 \\
\hline Referral to regional centre & $62(17.8)$ & $n=348$ & 57 (18.9) & $n=302$ & 0.78 \\
\hline
\end{tabular}

of the baseline model, which comprised gender, a discharge diagnosis of myocardial infarction, and the use of revascularisation (likelihood ratio test, $\mathrm{p}=0.03$ on $\mathrm{l}$ degree of freedom). This indicated that the observed influence of gender on rehabilitation, having adjusted for a discharge diagnosis of myocardial infarction, was modified by a history of hypertension: men with hypertension were twice as likely to undergo rehabilitation compared with women with hypertension (OR 2.01, 95\%CI 0.85 to 4.72). There was no significant gender difference in rehabilitation for normotensive patients (OR $0.64,95 \%$ CI 0.32 to 1.27 ).

Overall, patients with hypertension were less likely to undergo rehabilitation than normotensive patients (OR 0.67, 95\% CI 0.50 to 0.89 ) but this treatment difference did not apply in the same way to both men and women. Hypertensive women were nearly half as likely to undergo rehabilitation compared with normotensive women (OR 0.57, 95\% CI 0.33 to
0.98). This finding could not be explained by the older age of hypertensive women (age adjusted OR for hypertensive women compared with normotensive women 0.48 , 95\% CI 0.29 to 0.78 ). However hypertensive men were as likely as normotensive men to receive rehabilitation (OR 1.04, 95\%CI 0.49 to 2.20 ).

\section{Effect of potential confounders on the relation between} gender and CABG

The association between gender and the use of coronary artery bypass grafting (OR 1.90, 95\% CI 1.21 to 3.00) remained after adjusting for each potential confounder, both individually and cumulatively. No significant changes occurred in the odds ratio, which remained statistically significant. In other words, the effect of gender on CABG was not affected by the level of clinical need. No significant improvement in fit was found for any interaction term. 
Table 5 Investigations and procedures received by patients during the follow up period* $^{*}$

\begin{tabular}{|c|c|c|c|c|c|c|c|}
\hline \multirow[b]{2}{*}{ Exercise test } & \multicolumn{2}{|c|}{ Men $(n=382)$} & \multicolumn{4}{|c|}{ Women $(n=337)$} & \multirow{2}{*}{$\frac{\mathrm{p} \text { Value }}{0.6}$} \\
\hline & 162 & $(81.8)$ & $n=198$ & 134 & (79.8) & $n=168$ & \\
\hline Angiogram & 153 & (73.2) & $n=209$ & 127 & (71.8) & $\mathrm{n}=177$ & 0.75 \\
\hline PTCA & 51 & $(25.6)$ & $n=199$ & 50 & $(30.5)$ & $n=164$ & 0.30 \\
\hline CABG & 76 & (39.6) & $n=192$ & 42 & $(25.6)$ & $n=164$ & 0.005 \\
\hline Pacemaker & 3 & $(1.5)$ & $n=196$ & 2 & (1.3) & $n=156$ & 0.85 \\
\hline Transplant & 1 & (0.5) & $\mathrm{n}=194$ & 0 & & $\mathrm{n}=158$ & 0.37 \\
\hline Readmission & 191 & (50.7) & $\mathrm{n}=377$ & 162 & $(50.0)$ & $\mathrm{n}=324$ & 0.86 \\
\hline Mean number of times readmitted & \multicolumn{2}{|c|}{2.20} & $n=182$ & \multicolumn{2}{|c|}{2.05} & $n=158$ & 0.32 \\
\hline \multicolumn{8}{|l|}{ Waiting list } \\
\hline Exercise test & 15 & (6.9) & $n=218$ & 9 & $(4.7)$ & $n=190$ & 0.35 \\
\hline Angiogram & 7 & $(3.2)$ & $n=219$ & 5 & (2.7) & $n=183$ & 0.79 \\
\hline PTCA & 5 & $(2.8)$ & $n=218$ & 3 & $(1.6)$ & $\mathrm{n}=184$ & 0.45 \\
\hline CABG & 5 & $(2.3)$ & $n=216$ & 5 & (2.7) & $n=185$ & 0.80 \\
\hline Pacemaker & 0 & & $n=216$ & 2 & $(1.1)$ & $n=184$ & 0.13 \\
\hline Transplant & 0 & & $n=215$ & 1 & $(0.5)$ & $n=184$ & 0.28 \\
\hline
\end{tabular}

\section{Key points}

- Health care should be provided fairly in the NHS but there is evidence of gender bias in the use of cardiac services.

- Existing studies of the NHS are limited because they have used routinley collected data or have not examined the entire management pathway.

- This study investigated the complete management pathway of patients admitted to a random sample of hospitals, with acute ischaemia.

- No gender differences were found in the use of investigations or in revascularisation overall. However, the criteria used for selecting PTCA versus CABG requires further investigation as does the use of rehabilitation. It is unclear whether the clinical decisions to provide these procedures are made solely on the basis of clinical need.

\section{DISCUSSION}

\section{Findings}

There was little evidence of gender bias in the clinical management of patients admitted with an acute myocardial event. Women, who were older, were less likely to be diagnosed as having suffered an acute myocardial infarction and, not surprisingly, were therefore less likely to be sent for cardiac rehabilitation or CABG. These differences in management seem to be justified given the similar outcomes that men and women experience. The only gender inequity found was that hypertensive men were more likely to be referred for rehabilitation than hypertensive women even after adjusting for a discharge diagnosis of myocardial infarction and for the use of revascularisation (which is a common reason for referral for rehabilitation). This suggests that hypertension is taken more seriously in men than in women.

Men were significantly more likely to undergo CABG than women, a finding that could not be explained by the available indicators of clinical need. This was partly balanced by more women than men undergoing PTCA, although the difference was not significant. These gender differences may be attributable to gender differences in the number of coronary arteries diseased. We were unable to determine if this was the explanation as angiography results were not available.

\section{Methodological considerations and explanations}

This is the first study to take a random snapshot of the whole of the UK to investigate the management of a representative sample of acute cardiac patients. In addition, the entire clinical management pathway of patients admitted with acute ischaemia was examined, rather than restricting the examination to a limited number of health care interventions. Finally, this is one of the few studies to measure gender differences in quality of life after acute coronary events.

The study does, however, have several limitations. The potential weaknesses of the baseline study have been discussed elsewhere. ${ }^{16}$ Firstly, there are concerns that cases may have been selected by the hospital staff recruiting patients. However, the finding that in the pilot study (where consecutive cases were ascertained regardless of gender) the median duration to recruit six women was similar to that of the baseline sample offers considerable reassurance. Lack of data on non-recruited patients prevented any more detailed analysis of recruitment bias. Secondly, patients over 70 years were excluded because, when the study was planned, some hospitals operated an upper age limit for admission to a coronary care unit. Given the different age distribution of coronary heart disease between men and women, this might have biased the study. Thirdly, the lack of a clinical, electrocardiographic and/or biochemical case definition reflected our pragmatic aim, that is to record the reality of clinical practice. Thus, provided a diagnosis of acute myocardial infarction or myocardial ischaemia was the opinion of the admitting medical team, then the patient met their inclusion criteria. The baseline sample thus represented the full spectrum of clinical, electrocardiographic, biochemical, and radiographic features of acute ischaemic syndromes as currently diagnosed and treated in UK district general hospitals.

Accurate indicators of the need for revascularisation-that is, findings at angiography and the ejection fraction-were unavailable because follow up information was only collected from patients. ${ }^{22}{ }^{23}$ Instead, initial symptom severity was relied upon despite angina being only weakly associated with angiographic disease. ${ }^{24}$ In our defence, UK clinical guidelines emphasise the importance of symptom severity in guiding clinical decisions and symptom severity was the basis of an expert panel's ratings of appropriateness for angiography. ${ }^{25-27}$ A second concern was that indicators of disease severity measured at the index admission may not be indicative of the need for revascularisation when the decision to perform that procedure may be made up to three years later.

Another potential limitation was that it was not known whether the 122 non-responders who died received any treatment after discharge, and if so, if there were any gender differences. As there were no significant gender differences between the patients who replied and those who died, this factor is unlikely to have had any significant impact on the results.

The findings were limited in three ways by incomplete data. Firstly, use of echocardiography and isotope scanning during the follow up period, were not measured. This was because the pilot study revealed that these data were not reliably recorded 


\section{Policy implications}

- Our findings suggest that there is no need to change UK national policy regarding the use of exercise testing, angiography, and revascularisation for patients under 70 years old.

- However, if further prospective studies show that the criteria for choosing between percutaneous transluminal coronary angioplasty and coronary artery bypass grafting differs for men and for women, and that access to rehabilitation is not provided solely on the basis of clinical need, then there are important policy implications.

- These include developing transparent criteria for deciding between percutaneous transluminal coronary angioplasty and coronary artery bypass grafting, and for access to rehabilitation, and ensuring that these criteria are monitored.

by patients. Secondly, gender differences in revascularisation could only be examined in the $54 \%$ of responders who supplied the year of operation, to ensure that the analysis was restricted to procedures that took place after, and not before, the index admission. Finally, it was not feasible to measure the effect of full thickness ( $Q$ wave) infarction on the use of interventions because these data were not recorded for many patients. However, this is not an important indication of the need for revascularisation according to published guidelines. Given that the more important indicators of severity available for analysis did not influence the affect of gender, it is unlikely that infarct thickness would have had an important effect. ${ }^{17}$

\section{Relation to other studies}

No gender differences in the use of non-invasive investigations were found in this study of UK practice. This finding is important because a critical review of the international (but predominantly American) literature suggested that noninvasive testing may be the rate limiting step on the pathway to revascularisation

No statistically significant gender differences for angiography or PTCA were found. Previous studies report conflicting results. In common with previous research that did not take account of findings at angiography, this study found that men were more likely than women to undergo CABG.

Finally no significant gender differences in rehabilitation were found in two of the three previous studies undertaken, unlike this study which found gender differences for hypertensive patients. ${ }^{28-30}$

\section{Explanation and implications of findings}

The effect modifying influence of hypertension may have been a chance finding as it was the only one of 17 interaction terms added to the model that achieved significance. On the other hand, it is possible that because blood pressure is regularly monitored in hospital, this risk factor is more visible and so assumes greater significance compared with the other cardiac risk factors, when making decisions about referral for rehabilitation. Why this should result in the finding that women with hypertension are half as likely as normotensive women to be referred for this service, is unclear, but it merits further study of the influence of clinical judgement and of patient preference.

Use of clinical protocols may explain the lack of gender differences found in the use of investigations. The management of acute ischaemia was explicitly defined by protocols that were available when the study was undertaken, and that clinicians might, therefore, be expected to follow. ${ }^{26}$ Conversely, the existence of some inequity in referral for rehabilitation may reflect the absence of such explicit guidelines at the time that the patients were recruited, or a lesser regard for the importance of rehabilitation compared with the use of revascularisation. Gender differences in the use of PTCA and CABG could either reflect gender differences in the severity and extent of disease, or differences in clinical judgement.

These results have implications for policy makers. An extensive international literature has grown up around gender differences in the management of coronary artery disease, and editorials written in both the US and in the UK consistently refer to a gender bias in favour of men. ${ }^{31-33}$ Yet this national study found no gender differences in the investigations (exercise testing and angiography) or in revascularisation in patients under 70 years old. These findings, therefore, suggest that policy does not need to change. However, these results do raise two issues that require further investigation. Firstly, the criteria used for choosing between PTCA and CABG may differ for men and for women. Secondly, more prospective studies of access to rehabilitation are needed as it seems not to be provided solely on the basis of clinical need.

\section{ACKNOWLEDGEMENTS}

We thank the members of the SAMII Study Group who collected the data for the baseline survey. We also thank the MRC/NHSE London region for funding the Health services Research Fellowship that supported Rosalind Raine. Thanks also to Neil McLennan, the data manager for the baseline and follow up studies.

\section{Authors' affiliations}

R A Raine, N A Black, Department of Public Health and Policy, London School of Hygiene and Tropical Medicine, London, UK

T J Bowker, D A Wood, Department of Cardiovascular Medicine, National Heart and Lung Institute, Charing Cross Hospital, London, UK

Funding: Rosalind Raine was funded by the MRC/NHSE London Region.

Conflicts of interest: none.

\section{REFERENCES}

1 Raine R. Does gender bias exist in the use of specialist health care? J Health Serv Res Policy 2000;5:237-49.

2 Osmond C. Coronary heart disease mortality trends in England and Wales, 1952-1991. J Public Health Med 1995;17:404-10.

3 Central Health Monitoring Unit. Coronary heart disease. An epidemiological overview. London: HMSO, 1994.

4 Hemingway $\mathbf{H}$, Crook A, Feder $G$, et al. Is the investigation and management of coronary artery disease in women fair? A prospective study of patients undergoing coronary angiography. [Abstract]. In: Programe and abstracts of the Annual Scientific Meeting of the Society for Social Medicine. Sheffield: University of Sheffield, 1999:18.

5 Clarke K, Gray D, Keating N, et al. Do women with acute myocardial infarction receive the same treatment as men? BM 1994;309:563-6.

6 Hannaford P, Kay C, Ferry S. Ageism as explanation for sexism in provision of thrombolysis. BM 1994;309:573.

7 Adams J, Jamieson M, Rawles J, et al. Women and myocardial infarction: agism rather than sexism? Br Heart J 1995;73:87-91.

8 Tunstall-Pedoe H, Morrison C, Woodward M, et al. Sex differences in myocardial infarction and coronary deaths in the Scottish MONICA population of Glasgow 1985-1991. Circulation 1996:93:1981-92.

9 Raine R,Crayford T, Chan K, et al. Gender differences in the investigation and treatment of patients with a diagnosis of cardiac pain in England. BM 1998;316:391.

10 Kee F. Referrals for coronary angiography in a high risk population. Quality in Health Care 1993:2:87-90.

11 Majeed F, Cook D. Age and sex differences in the management of ischaemic heart disease. Public Health 1996;1 10:7-12.

12 Petticrew M, McKee M, Jones J. Coronary artery surgery: are women discriminated against? BM 1993;306:1164-6.

13 Black N, Langham S, Petticrew M. Trends in the age and sex of patients undergoing coronary revascularisation in the United kingdom. Br Heart J 1994;72:317-20

14 Dong W, Ben-Shlomo Y, Colhoun H, et al. Gender Differences in accessing cardiac surgery across England: a cross sectional analysis of the Health Survey for England. Soc Sci Med 1998:47:1773-80.

15 Kee F, Gaffney B, Currie S, et al. Access to coronary catheterisation: fair shares for all? BM 1993;307:1305-7

16 Bowker T, Turner R, Wood D, et al on behalf of the SAMII Study Group. A national Survey of Acute Myocardial Infarction and Ischaemia (SAMII) in the UK: characteristics, management and in-hospital outcome in women compared to men in patients under 70 years. Eur Heart $J$ 2000;21:1458-63

17 Gunnar R, Bourdillon P, Dixon D. Guidelines for the early management of patients with acute myocardial infarction: a report of the American College of Cardiology/American Heart Association Task Force on assessment of diagnostic and therapeutic cardiovascular procedures 
Isubcommittee to develop guidelines for the early management of patients with acute myocardial infarction. J Am Coll Cadiol 1990;16:249-92.

18 Valenti L, Lim L, Heller R, et al. An improved questionnaire for assessing quality of life after acute myocardial infarction. Qual Life Res 1996:5:151-61.

19 Carstairs V. Morris R. Deprivation and health in Scotland. Aberdeen: Aberdeen University Press, 1991.

20 Kahn H, Sempos C. Statistical methods in epidemiology. New York: Oxford Univeristy Press, 1989

21 SPSS. SPSS Windows 8.0. Cary: SPSS Inc, 1998

22 Weiner D, Ryan T, Parsons L. long term prognostic value of exercise testing in men and women from the Coronary Artery Surgery Study (CASS) registry. Am J Cardiol 1995;75:865-70.

23 Ringqvist I, Fisher L, Mock M. Prognostic value of angiographic indices of coronary artery disease from the Coronary Artery Surgery Study (CASS). J Clin Invest 1983;71:1854-66.

24 Proudfit W, Shirey E, Sones F. Selective cine coronary arteriography: correlation with clinical findings in 1000 patients. Circulation 1966;33:901-10

25 De Bono D, Hopkins A. The investigation and management of stable angina. Report of a working party of the Joint Audit Committee of the British Cardiac Society and the Royal College of Physicians London. J R Coll Physicians Lond 1993;27:267-73.
26 De Bono D. Hopkins A. A report of a workshop of the Joint Audit Committee of the British Cardiac Society and the Royal College of Physicians: the management of acute myocardial infarction: guidelines and audit standards. J R Coll Physicians Lond 1994;28:312-17.

27 Hemingway $\mathbf{H}$, Crook A, Dawson J, et al. Rating the appropriateness of coronary artery angiography, coronary angioplasty and coronary artery bypass grafting; the ACRE study. J Public Health Med 1999;21:421-9.

28 Ades P, Waldmann M, Polk D, et al. Referral patterns and exercise response in the rehabilitation of female coronary patients aged $>62$ years. Am J Cardiol 1992;69:1422-5.

29 Thomas R, Miller N, Lamendola C, et al. National survey on gender differences in cardiac rehabilitation programs. Patients characteristics and enrollment patterns. Journal of Cardiopulmonary Rehabilitation 1996; 16:402-12

30 Pell J, Pell A, Morrison C, et al. Retrospective study of the influence of deprivation on uptake of cardiac rehabilitation. BM 1996;311:267-8.

31 Jackson G. Coronary artery disease and women. BM 1994;309:226-7.

32 Wenger N. Coronary heart disease: an older woman's major health risk. BM 1997;315:1085-90.

33 Healy B. The Yentl syndrome. N Engl J Med 1991;325:274-5. 